\title{
Scientific, Regulatory and Practical Approaches to the Fight against Counterfeit Medicinal Products. Bulgarian Experience
}

\author{
Emil Hristov ${ }^{1}$, Zlatka Dimitrova ${ }^{1}$, Iva Parvova ${ }^{2}$ and Borislav Kitov ${ }^{3}$ \\ 1. Faculty of Chemistry and Pharmacy, Sofia University "Saint Kliment Ohridski", Sofia 1504, Bulgaria \\ 2. Department of Internal Medicine, Medical University of Sofia, Sofia 1431, Bulgaria \\ 3. Department of Neurosurgery, Medical University of Plovdiv, Plovdiv 4002, Bulgaria
}

\begin{abstract}
Over the recent years, there has been an alarming increase in the market penetration of the so-called "counterfeit" medicinal products in the European Union and worldwide. These products usually contain substandard (lower quality) or false ingredients, do not contain the necessary ingredients, or contain substances or active pharmaceutical ingredients, which are wrongly or incorrectly dosed. Bulgarian experience has shown that the counterfeit medicinal products enter the market not only through illegal channels, but are also distributed in and/or through lawful channels and distribution chains of medicinal products manufacturers (importers), wholesalers and retailers (pharmacies and drugstores). A special phenomenon is the distance selling of medicinal products, including on-line marketing (internet trade) - perhaps the riskiest way the counterfeit medicinal products reach the patients. Counterfeit medicinal products are one of the most significant threats to human health and their market penetration can lead to loss of confidence in the drug distribution systems and in the public health system as a whole.
\end{abstract}

Key words: "Counterfeit" medicinal products, "falsified" medicinal product, lawful distribution chains, illegal chains, on-line marketing (internet trade).

\section{Introduction}

The problem with the market penetration of counterfeit medicinal products was first discussed internationally in 1985 at the Conference of experts on rational drug use, organized by the World Health Organization (WHO) in Nairobi, Kenya. The final document adopted by the Conference recommended that WHO, together with the international institutions, national competent regulatory authorities and non-governmental organizations (NGOs), should investigate thoroughly the issue of the entry of counterfeit medicinal products and inform the Governments of the Member States of the nature and extent of the spread of counterfeit drugs [1].

Corresponding author: Zlatka Dimitrova, Ph.D., MSc, professor, research fields: social pharmacy, pharmacoeconomics.
In 1988, the World Health Assembly (WHA) adopted Resolution WHA41.16, which required from the WHO Director-General to initiate programs for prevention and detection of smuggling routes for import, export and distribution of wrongly packed, falsified or substandard pharmaceutical products.

Considering the increasingly growing market entry of counterfeit drugs worldwide and their availability in the national drug distribution systems, in 1994 WHA adopted a new resolution WHA47.13. This resolution urges and orders WHO to assist the Member States in their efforts to ensure the quality of the available drugs and organize and support the fight against counterfeit medicinal products [1].

The Internet expansion in the everyday life gave birth to a special phenomenon-distance selling, including on-line marketing of medicinal products. Many analysts in the pharmaceutical sector believe and 
prove that on-line marketing is probably the riskiest way the counterfeit medicines reach the patient and ranks first among the channels of entry and distribution of products of unknown origin [2].

In 2006, considering the massive influx of counterfeit medicinal products in the markets of Asia, Africa and developing countries (e.g. the data for Nigeria are striking-75\% of the market is occupied by counterfeit medicines), WHO announced the IMPACT (International Medical Products Anti-counterfeiting Taskforce) initiative as its essential tool and a method of fighting against counterfeit medicinal products [3, 4].

Despite the efforts made by WHO between 1988 and 2006, modern and conservative Europe arrogantly underestimated the seriousness of the problem and its threat to public health. Although Member States participate in the WHO initiatives, it was believed that the counterfeit drug problem concerned mainly the third world countries and the EU did not take adequate measures and initiatives.

The globalization processes in general, and particularly the issue of counterfeit medicinal products could not pass the EU Member States, and in 2000 they began to announce numerous cases of counterfeit drugs entering Europe. The European Parliament responded to this situation and adopted a special resolution on the issue defining the following tasks: European Union (EU) must take urgent measures to effectively combat counterfeit medicinal products; EU must take steps to strengthen the regulatory and quality control of medicinal products; EU must play a key role in the development of a system criminalizing the delivery and distribution of counterfeit drugs and take actions to change the legislation in each Member State; EU must enhance the cooperation between various competent authorities at national and international levels, take specific measures against the market entry of counterfeit medicinal products and work out an action plan [5].

The European Commission's (EC) reply was quick — on May 14, 2007 during the First European Parliamentary Symposium "Putting an end to Drug Counterfeiting", EC Vice-Chairman Commissioner Guenter Verheugen defined the so-called "EC Statement" and put the beginning of thorough analysis of the problem and active work to change in European legislation, which ended in the adoption of Directive 011/62/EU of the European Parliament and of the Council of 8 June 2011 amending Directive 2001/83/EC on the Community code relating to medicinal products for human use, as regards the prevention of the entry into the lawful supply chain of falsified medicinal products [6-8].

\section{Defining the "Counterfeit Medicinal Products" Problem}

Over the years, there have been many studies to assess the "falsified medicinal products" issue by various national and international bodies, institutions and NGOs, associations of pharmaceutical companies, business associations etc. Unfortunately, all these studies and analyses focused only on certain specific aspects of the problems and did not consider their extremely diverse nature.

Perhaps the best designed and comprehensive analysis is the Working Document "Impact Assessment" published by the Commission on 10.12.2008 and submitted to broad discussion within the EU, accompanying the EC proposal for a new Directive [7].

EU Member States, European Commission with concerned Directorate Generals and agencies, all stakeholders in the pharmaceutical sector, WHO, third countries, international governmental and non-governmental organizations took part in the development and discussion of the working document. We consider it important to note Bulgaria's active participation and extensive factual material, provided by the relevant Bulgarian institutions, part of which was quoted directly and found its place in the final working document $[7,9]$. 


\subsection{How Big Is the Problem?}

Working document "Impact Assessment" clearly indicates that the pharmaceutical sector is strategic for Europe as part of the public health system, generates positive effects on the European economy and improves public welfare. Currently, more than 3,700 pharmaceutical companies with an annual turnover of over $€ 170$ billion are operating in the European market, and this sector employs over 634,000 people. 1000 out of these companies are generic, and about 1000 manufacture over-the-counter drugs (OTC). Besides pharmaceutical manufacturers, in the pharmaceutical market, there are other "Players"-API suppliers, importers, wholesalers, including "parallel" traders, retailers - pharmacies and drugstores, brokers etc. In other words, the pharmaceutical sector is structurally defining for Europe and any breach of trust in it (in this case, counterfeit medicinal products) will result in immeasurable negative consequences for society as a whole [7].

\subsection{Is There an Increase of Counterfeit Medicinal} Products in the Market?

According to Eurostat, there is a drastic increase in the quantities of seized consignments of counterfeit medicinal products on the European borders. In 2006, 2711410 consignments were seized, which is an increase by $384 \%$ compared to 2005 . In 2007 , these growth rates remain the same. WHO expert group evaluating the problem, estimated the market share of counterfeit medicinal products in industrialized countries to no more than $1 \%$. The industry, however, believes that the volume of counterfeit medicinal products on average increases from $20 \%$ to $100 \%$ annually [5-7]. The data on Bulgaria (as stated in the report) show 5 cases in 2005 and an increase to 15 cases in 2007, which represents a growth rate of $300 \%$ in 3 years $[2,6,7]$. The data on United Kingdom (as stated in the report) indicate lack of incidents up to 2004 and then 9 cases of finding counterfeit medicinal products in the lawful distribution chains until
2007 [7].

\subsection{Types of Counterfeit Medicinal Products and} Routes of Distribution.

The European Commission established criminal activities targeted to the counterfeiting of life-saving medicines used for treatment of cancer, cardiovascular diseases, mental disorders and infectious diseases. The reports mentions that the major routes of entry of counterfeit medicinal products are on-line marketing, entry into the lawful distribution systems, import of substandard active ingredients, parallel trade, etc. The report states that the penetration of counterfeit medicinal products in the lawful distribution chains is an objective fact.

In the EU, there has been a long and pointless discussion whether counterfeit medicinal products enter the lawful distribution chains or are distributed through illegal channels. Considering the fundamental fact that the EU citizens are the end point of the lawful drug distribution chain and that the aim of manufacturers and suppliers of counterfeit medicinal products are objectively also EU citizens, this discussion certainly loses its meaning.

Our view is that the task of regulators and national competent authorities is to provide EU citizens with high quality, effective and safe medicinal products and the individual citizen cannot be considered as the end point of both lawful or illegal chain [7-10].

\section{WHO's Scientific, Regulatory and Practical Approach to the Fight against Counterfeit Medicinal Products}

WHO initiate IMPACT (International Medicinal Products Anti-counterfeiting Taskforce) sets the following purposes:

(1) Improve cooperation between governments, organizations, institutions, agencies and associations involved in the fight against counterfeit medicinal products at national, regional and/or international level.

(2) Considering the global distribution of counterfeit 
medicinal products - establish and improve the interaction between international organizations and participants in the pharmaceutical sector.

(3) Establish adequate international cooperation aiming at the development of effective legislation to combat counterfeit medicinal products.

(4) Create effective information exchange mechanisms.

(5) Build technical and administrative capacity to create and promote international, regional and national strategies.

(6) Improve the coordination between different initiatives to combat counterfeit medicinal products.

Working Groups were created within IMPACT: Legislative and Regulatory Infrastructure Group; Regulatory Implementation Group, Technological Group; Information Exchange Group and Group on implementation and enforcement of the measures taken. After two years of work, on December 12, 2007, the final document of the initiative, better known as the Lisbon Strategy, was adopted at the IMPACT General Meeting. The final document is entitled "Principles and Elements for National Legislation against Counterfeit Medical Products". Lisbon Strategy specifies and introduces new definitions of medicinal product, counterfeit medicinal products, manufacturer and operators in distribution channels (broker, distributor, exporter, importer, retailer, sales agents and representatives). Lisbon Strategy also specifies the duties and responsibilities of public authorities, institutions and all stakeholders involved in the pharmaceutical sector, formulates the duties at the regional and national level, offers definitions of illegal activities and sets the target of the administrative actions and criminal sanctions [3, 4]. A two-year survey of the national legislation systems, including WHO Member States, ended in 2009. The results were more than interesting - a complete lack of common understanding and establishment of uniform rules in the fight against counterfeit medicinal products, divergence in the definition of the problem, various definitions, etc. This study retrospectively confirmed the correctness of the WHO decision to create IMPACT initiative. WHO takes strong stance that the phenomenon of the "counterfeit medicinal products" can be fought efficiently only through effective coordination and international cooperation $[1,3,4,11]$.

\section{EU's Scientific, Regulatory and Practical Approach to the Fight against Counterfeit Medicinal Products}

EU's scientific and regulatory understanding of the fight against counterfeit medicinal products was presented in Directive 2011/62/EU of the European Parliament and of the Council of 8 June 2011 amending Directive 2001/83/EC on the Community code relating to medicinal products for human use, as regards the prevention of the entry into the lawful supply chain of falsified medicinal products [8]. The Directive establishes a single definition of "falsified medicinal product" for all Member States, and defines the terms "active ingredient" and "excipient" (auxiliary substance).

Individuals and legal entities, who supply medicinal products, hold, store, supply or export such products, may carry out the described activities only if they meet the requirements for obtaining a wholesale trade license in accordance with Directive 2001/83/EC. This puts an end to the operation of unlicensed retailers and chain of intermediaries. The Directive offers the creation of European database for wholesalers of medicinal products and strengthens control and inspection measures, which leads to creation of the necessary harmonized principles and guidelines for inspections of wholesalers. The Directive introduces strict rules on control and inspection of manufacturers of active pharmaceutical ingredients. Notification regime is established. It also adopts the regulations on Good Manufacturing Practice in the manufacturing of auxiliary substances. The Directive requires the Member States to exercise close control over the 
import and export of medicinal products through duty free zones. It introduces the identification and definition of safety indicators for prescription medicines and initiates the creation of tracking system for drug sales.

Special attention is paid to on-line marketing (internet trade) - but in view of the European Court's practice and the fact that European legislation does not cover retail trade in medicinal products, the main responsibilities are left to be settled by the national laws.

The Directive does not cover the issues of the intellectual property and its main purpose is to prevent the introduction of counterfeit medicinal products in the lawful supply chain. The Directive's purpose would be much more logical and ambitious if it was directed to the full overcome of the "counterfeit medicinal products" problem.

\section{Now the Impression Is that There Is Nothing Wrong with the Counterfeit Medicinal Products as Long as They Do Not Reach the Legal Chains!}

We can definitely say that the adoption of the Directive is a huge step in the right direction, but its final version does not match the extremely high goals and objectives in the fight against counterfeit medicinal products, which were set at the beginning.

Free movement of active pharmaceutical ingredients on the market is one of the main prerequisites for counterfeiting medicinal products. The Directive, however, restricts but does not put an end to the liberal nature of this market sector. The measures proposed to control on-line marketing are more desirable than practical.

The comparative analysis between current Bulgarian Medicinal Products in Human Medicine Act (MPHMA) and the new Directive definitely reveals that MPHMA introduces much more stringent and effective measures to combat effectively drugs counterfeiting $[7,12,13]$.
6. Bulgaria's Scientific, Regulatory and Practical Approach to the Fight against Counterfeit Medicinal Products

Modern Bulgarian pharmaceutical legislation definitely started in 1995, when the National Assembly of the Republic of Bulgaria adopted the first Pharmaceuticals and Pharmacies in Human Medicine Act (PPHMA) [12].

PPHMA promulgation was followed by the adoption of various regulations related to the so-called counterfeit drugs, even though the law did not introduce the definition of counterfeit medicinal products.

The accession of Bulgaria to the EU in January 2007 led to harmonization of Bulgarian legislation on medicinal products for human use to EU law, which led to the development of entirely new Medicinal Products in Human Medicine Act adopted by the National Assembly on 13.04.2007 [13].

PPHMA of 1995 and MPHMA of 2007 use the term "Unauthorised medicinal products", which makes it possible to resist effectively market penetration of so-called "counterfeit medicinal products" and fight violators of drug laws, whether lawful or illegal. The new Law permits production, import, wholesale and retail, advertising and treatment, prevention and diagnosis only with medicinal products that are authorized for use under the Act. Retroactively, all subjects and products, which have not received authorization under this Act, will be considered unauthorized.

The term "Unauthorised medicinal products" includes:

(1) Medicinal products that are undergoing authorization procedure, which is not completed!

(2) Products of unknown origin - these are products that correspond to the authorized product, but: the manufacturer cannot be identified; there are no supporting documents of origin and financial and accounting documents to track the distribution chain; they do not have a certificate of batch release and 
quality control.

(3) Food additives, which directly claim that they can be used for prevention, treatment and diagnosis of human diseases, such as dietary supplements of plant origin.

(4) Cosmetic products.

(5) Medical products containing active ingredient.

(6) Counterfeit medicinal product: WHO definition was used until August 2008, even though it was introduced to the legislation.

This interpretation of the legislation allows for effective measures against counterfeit medicinal products $[9,12,13]$.

Both Acts were followed by Regulations on Good manufacturing practice, Good distribution practice, Good pharmacy practice, Ordinance on blockage and withdrawal of medicinal products from manufacturers, wholesalers, retailers and medical and health institutions, concerning products, which do not comply with quality, efficiency and safety requirements, etc. These ordinances provide adequate measures against counterfeit medicinal products.

It is extremely important to mention that the tracking system for monitoring of each batch of products was introduced in 1995 and it has been operating ever since. Each marketed batch must be accompanied by a certificate of batch release and financial and accounting documents (invoices, etc.) as to allow the tracking of the route from the manufacturer through wholesales to retailers-pharmacies and drugstores [12].

Moreover, in Bulgaria, there is unique national system of blocking medicinal products that have shown documented non-compliance with quality, efficacy and safety requirements, products imported or manufactured in violation of the law, as well as medicinal products that are available in packs with leaflets, which do not meet the legal requirements; when necessary, these products are withdrawn from pharmacies, drugstores, wholesale warehouses, manufacturers and medical institutions $[12,13]$.
In the cases above, Bulgarian Drug Agency (BDA) issues blockage order or blockage and withdrawal order. The order is published on BDA website and the population is informed through the national media. The guilty parties, all manufacturers, wholesalers and retailers are responsible for the blockage and withdrawal. BDA and Regional Health Inspections (RHI) at the Ministry of Health control the procedure. The retailers - pharmacies and drugstores must notify each patient, who has bought any medicinal product subject to blockage and withdrawal .

Despite the facts above, in August 2008 the National Assembly amended MPHMA to introduce the definition of "falsified medicinal products" and did this three years before the EU adopted uniform definition for the Member States by Directive 2011/62/EU. And as the Directive orders, the Member States must transpose it to their legislation until 02.01.2013.

The following definition is introduced: "Counterfeit medicinal product" is a medicinal product with false identification data stated on the product, its primary or secondary package or leaflet (e.g. misleading statement about its name, composition, amount of active ingredient in dose unit or other elements), false history or origin (e.g. misleading statement about its manufacturer, the country, in which it is manufactured, country of origin or marketing authorization holder). Counterfeit medicinal product may contain correct ingredients or other ingredients, not containing an active ingredient, or it may contain the active ingredient in any incorrect amount, or it may have counterfeit packaging. The lawfully authorized medicinal products with quality defects or those not complying with the Good Manufacturing Practice requirements and/or Good distribution practices should be distinguished from the counterfeit medicinal products [13].

In other words, practice and experience show that Bulgaria is significantly ahead of the EU Member States in modernizing its legislation on counterfeit medicinal products, and Bulgarian competent national 
authorities have extensive experience in this field, both as scientific research and implementation of practical measures to identify, detect and combat counterfeit medicinal products, in close cooperation with police, prosecutors and civil society institutions [10]. This is also evidenced by the achieved results, as it will be mentioned below $[2,9,14]$.

From 2004 to 2005, there are 5 identified cases of distribution of counterfeit medicinal products on Bulgarian market (Table 1) [2, 7, 9, 10].

From 2006 to 2007, the number of cases of detected counterfeit medicinal products increased to 15 . Some of these cases were very interesting and changed not only Bulgarian but also European authorities' understanding on the pathways, manufacturing, import, prescription and dispensing of counterfeit products, the secret on-line marketing mechanisms and the way the counterfeit products reach the individual patient.

The so-called "life style" medicinal products - weight loss drugs, erectile dysfunction treatment, etc. have been considered as the main counterfeit target for a long time (Figs. 1 and 2) [2,9].

Bulgarian experience shows, however, that if at the beginning the first discovered counterfeit medicinal products were like the examples above, later counterfeiting expanded to mainly original medicinal products under patent protection in a period of exceptional data protection, which were used for treatment of emergency conditions, cardiovascular diseases, chronic diseases, life-threatening conditions, etc $[2,9]$.

One of the most interesting cases of finding a counterfeit product on Bulgarian market is the so-called "Tertensif SR case". There is collected evidence that more than 2,000 packs of this medicinal product were launched to the market $[2,9]$. Besides the visible difference in the pack and package leaflet, the analysis of the qualitative and quantitative composition

Table 1 Identified cases of counterfeits on Bulgarian market (2004-2005).

\begin{tabular}{lll}
\hline Date & Trade Name and Pharmaceutical Form & International Nonproprietary Name INN) \\
\hline August 20, 2004 & Tertensif 2.5 mg film-coated tablets $\times 30$ & Indapamide \\
September 1, 2004 & Biseptol 480 mg tablets $\times 20$ & Sulfamethoxazole, Trimethoprim \\
October 6, 2005 & Biseptol 480 mg tablets $\times 20$ & Sulfamethoxazole, Trimethoprim \\
October 6, 2004 & Benalgin tablets $\times 20$ & Caffeine, Metamizole sodium, Thiamine hydrochloride \\
October 13, 2005 & Benalgin tablets $\times 20$ & Caffeine, Metamizole sodium, Thiamine hydrochloride \\
\hline
\end{tabular}

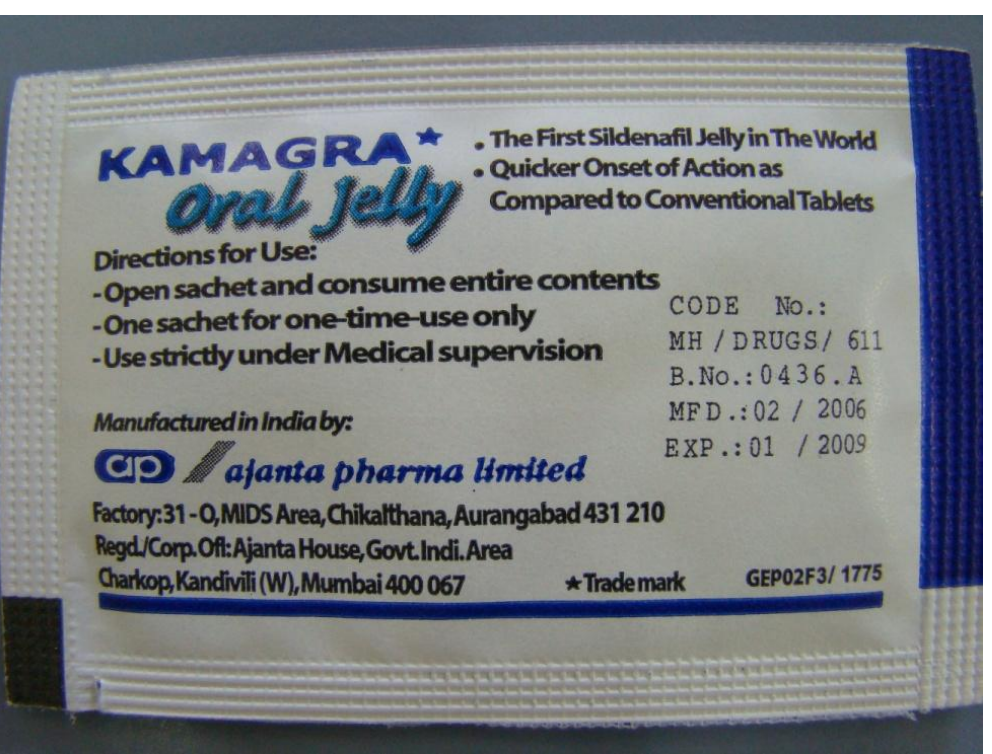

Fig. 1 Example of counterfeit medicinal product containing Sildenafil. The manufacturer indicated on the pack does not exist. 


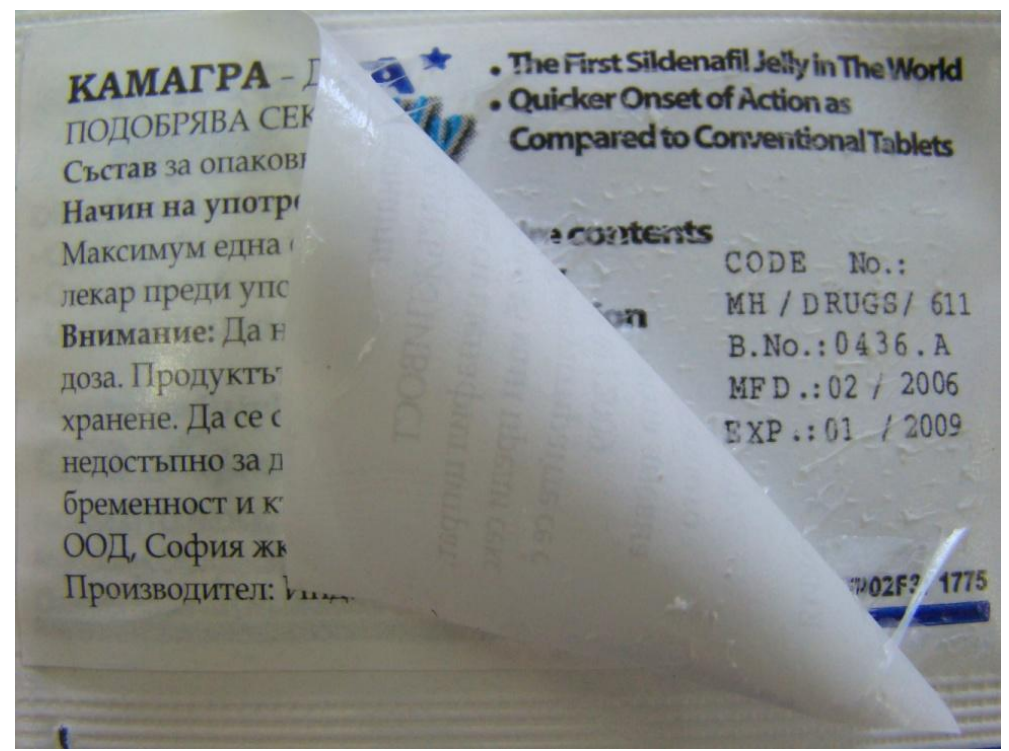

Fig. 2 The counterfeit product was repacked with Bulgarian label and marketed as a dietary supplement. The active ingredient it contains is available only with prescription.

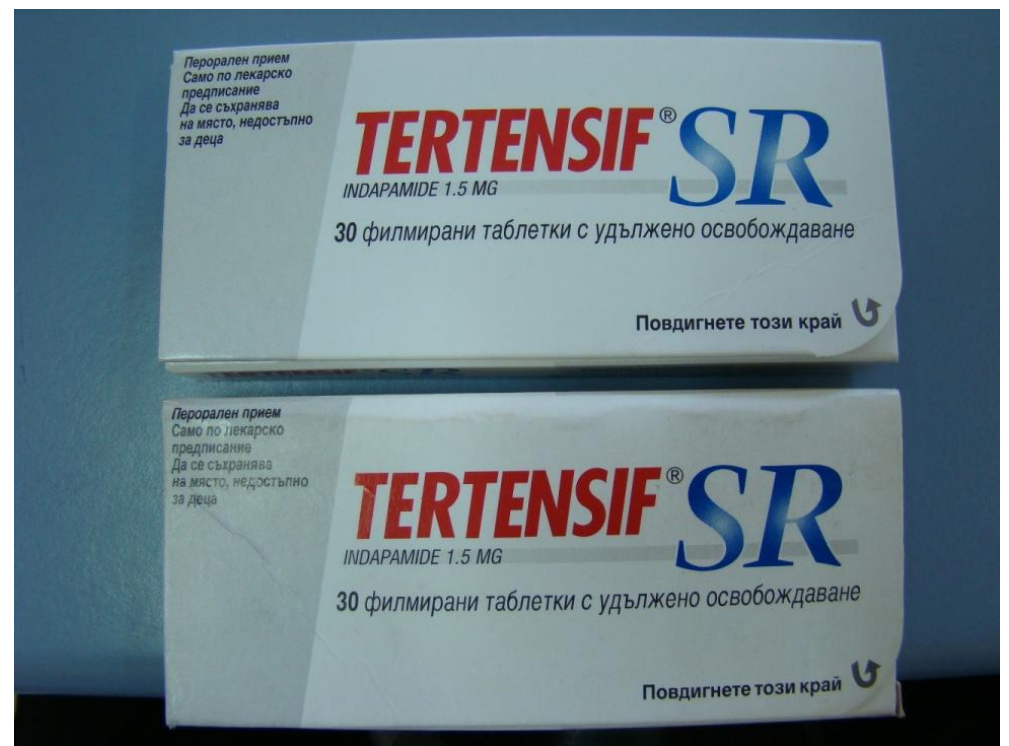

Fig. 3 Case of detected counterfeit medicinal product used for treatment of arterial hypertension-INN Indapamide.

of the counterfeit showed that it contained substandard amount of active ingredient. Instead of active ingredient with sustained release, it was found that the product contained Indapamide with normal release and it was in a minimum amount (Figs. 3-5).

The drift of the counterfeiting process to drugs for treatment of chronic and acute diseases is the most serious threat, as there is way to determine the severity of the threat and damage to both the health of individual patients taking the counterfeit medicine and the health of the population.
Considering "Tertensif SR case" in particular, there is no way to establish the number and nature of the complications in the patients, who took the counterfeit product. It is obvious that these patients did not adequately control their arterial hypertension. It is possible that some of them were even hospitalized. The method to determine the number of the patients, who received this product is still unknown. But if we accept that a manufacturing batch consists of about 100,000 packs (which is the usual number of the lawful batches), we can speculatively assume that some undiscovered 


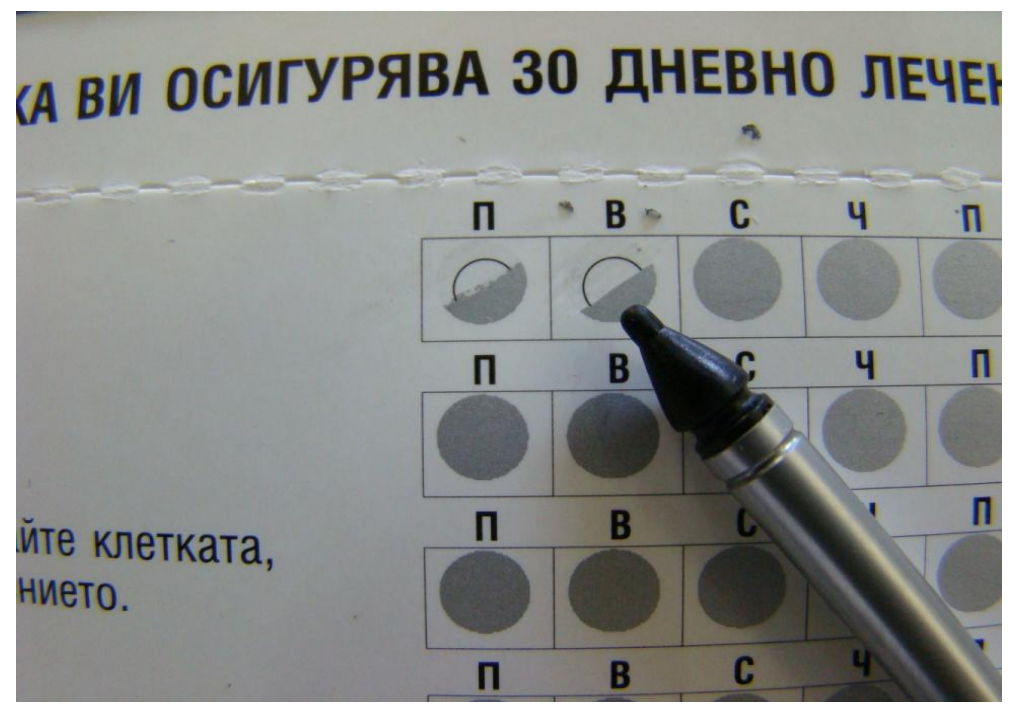

Fig. 4 Original product-patient self-control calendar, part of the pack.

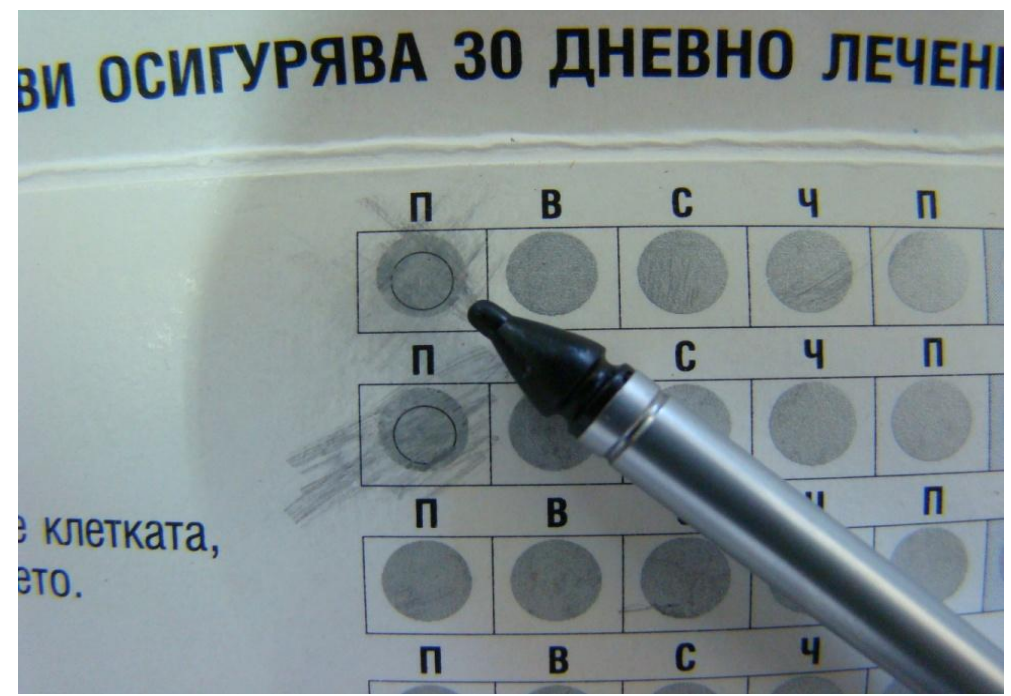

Fig. 5 Counterfeit product - self-control calendar-the patient cannot erase the week days.

packs still remain on the market and the supervisory authorities have found the counterfeit too late.

How many patients have been exposed to this unpredictable risk?

It is difficult to determine the costs using health economics (pharmacoeconomics) criteria of direct and indirect costs calculation, but one thing is certain - they are significant.

\section{Do We Touch Only the "Tip of the Iceberg" of the Counterfeit Medicinal Products?}

The last case we present here is one of the most significant BDA successes in the fight against counterfeit medicinal products and shows the entire route of the on-line marketing of counterfeit products. It concerns a network of wholesalers located in the duty free zones in different countries-India, Turkey, Norway, Canada, Netherlands Antilles, Switzerland, UK, etc. All wholesalers are registered under the laws of the respective country. They receive on-line purchase orders of drugs and have a unified software for implementation of the orders-Pharma Back Office and Rx Fill. If any of the wholesalers do not have the ordered drug, it automatically forwards to order to another wholesaler in the network (Fig. 6). 


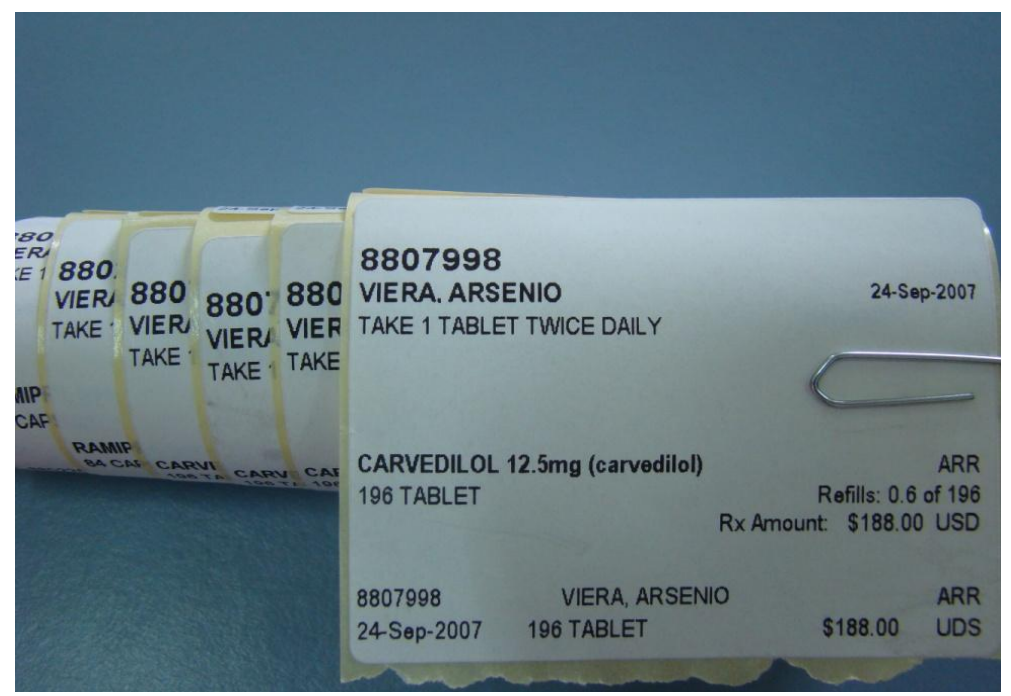

Fig. 6 Automatic labeling immediately after receipt of the purchase order.

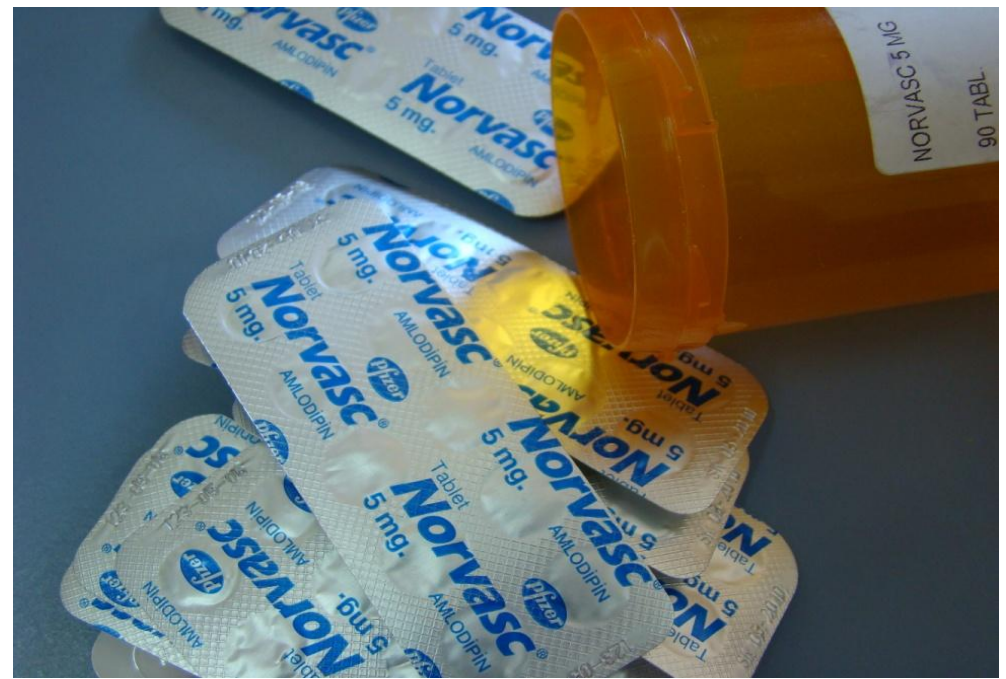

Fig. 7 Norvasc, INN Amlodipin, ready to be packed.

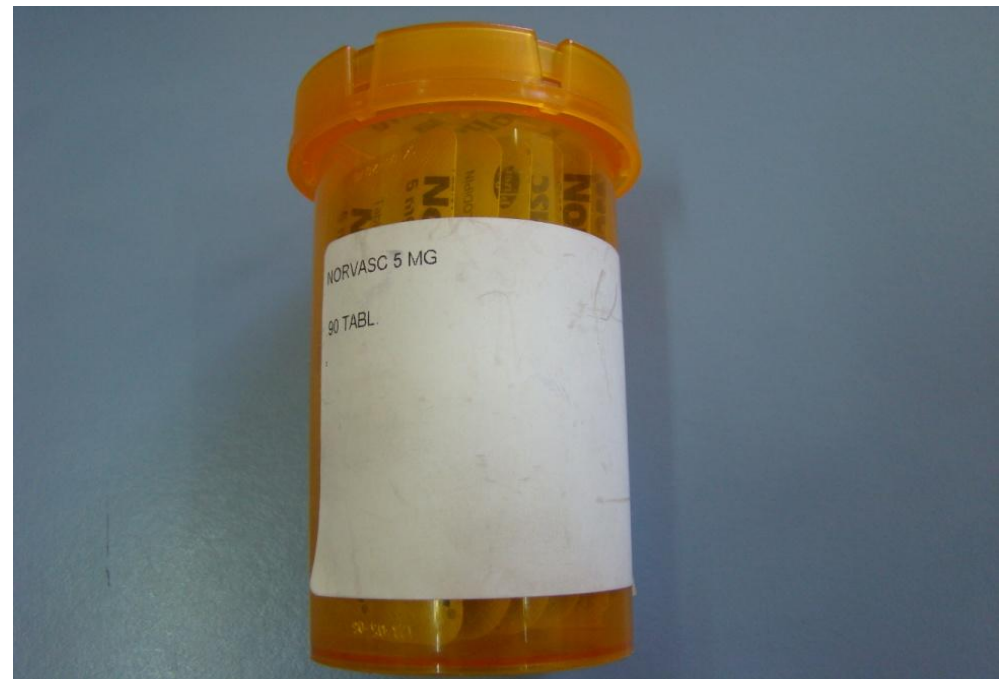

Fig. 8 Norvasc packed in individual bottle and respectively labeled. 


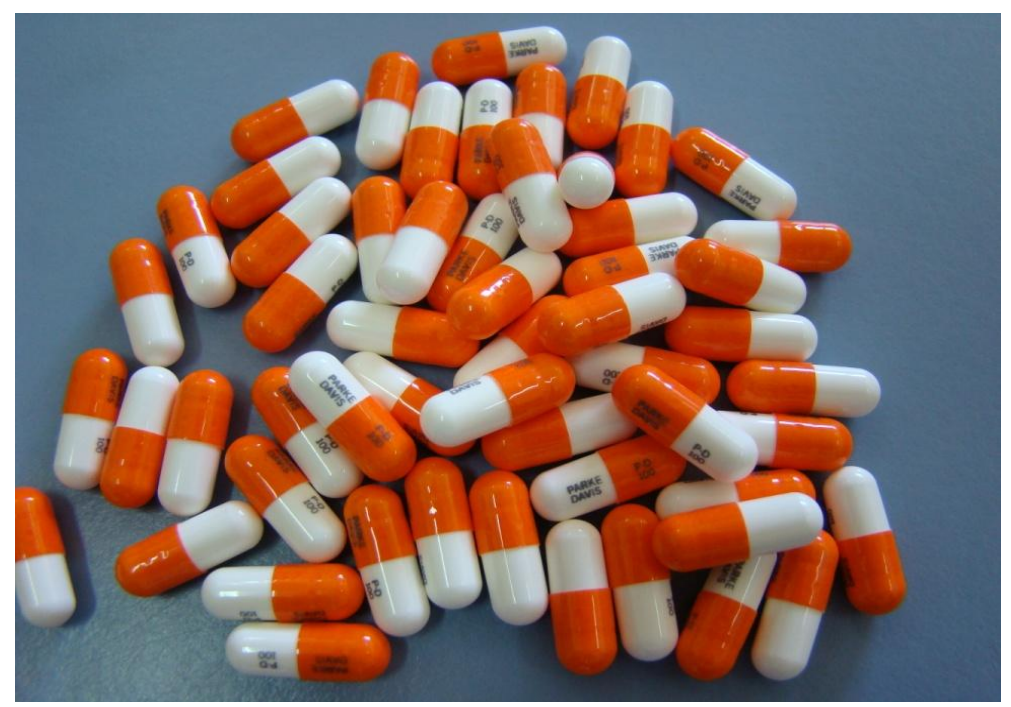

Fig. 9 Norvasc in bulk.

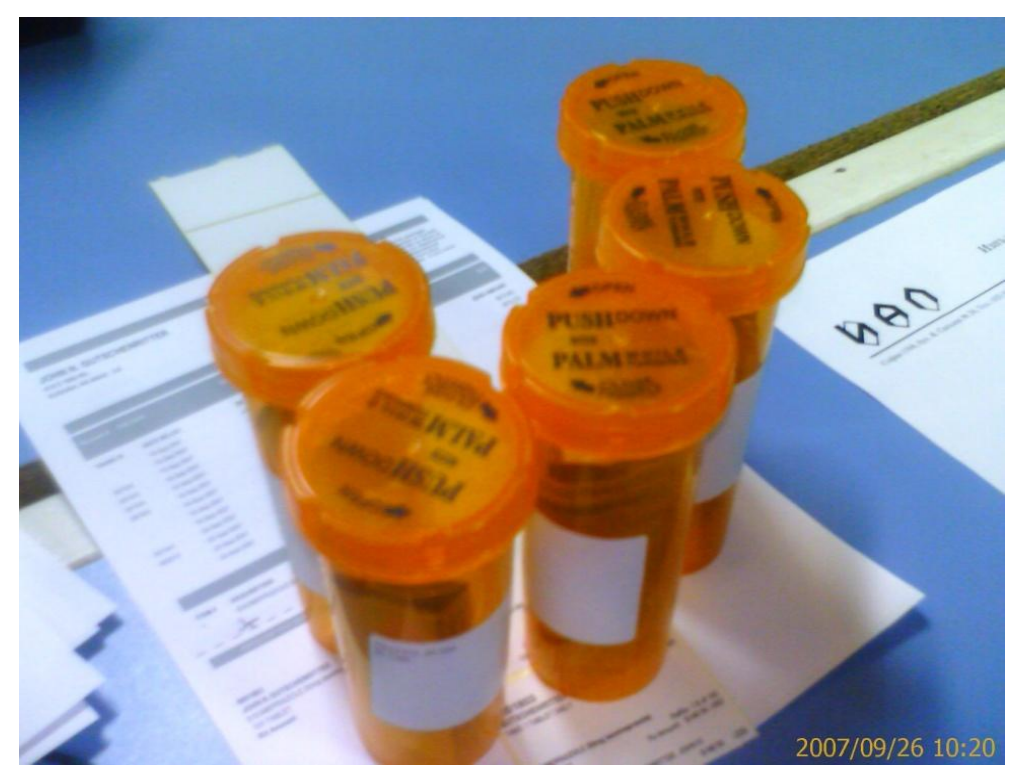

Fig. 10 Supply with supporting documents ready to be forwarded.

Orders are processed automatically. The ordered drug is packed in an individual bottle and all necessary documents for forwarding to the specific address, including customs documents and prescription, are issued. Of course, these documents are as counterfeit as the drugs (Figs. 7-10).

\section{Conclusion}

The "counterfeit medicinal products" issue is one of the greatest challenges to modern regulatory science and practice. In this article, we have outlined the main guidelines developed by WHO, EU and Bulgarian research and practical experience. Are the undertaken measures adequate and prompt? Is drug legislation adequate and sufficiently stringent to protect patients from counterfeit medicinal products? These questions may sound rhetorical, but we should seek their answers because we face this new challenge in the global world.

In conclusion, we believe that we can fight successfully "counterfeit" medicinal products to ensure high-quality, effective and safe medicines on global market only through the efforts of the entire international community and society with all their available political, social and economic resources, 
under the guidance of the drug regulatory authorities.

\section{Competing Interests}

All authors declare: no support from any organization for the submitted work; no financial relationships with any organizations that might have an interest in the submitted work in the previous 3 years; no other relationships or activities that could appear to have influenced the submitted work.

\section{References}

[1] World Health Organisation. 1999. "Counterfeit Drugs. Guidelines For The Development Of Measures To Combat Counterfeit Drugs." Accessed January 10, 2015. http://apps.who.int/medicinedocs/en/d/Jh1456e/

[2] Hristov, E, and Kulaksazova, R. 2008. "Bulgarian Drug Agency experience with Counterfeit Medicines." Presented at Best Practice Session of the 53th Meeting of Heads of Medicine Agencies, Brdo, Slovenia.

[3] World Health Organisation. 2006. "International Medical Products Anti-counterfeiting Taskforce (IMPACT). Terms of Reference." Accessed February 01, 2015. http://apps.who.int/impact/about/IMPACT_ToR.pdf?ua= 1

[4] World Health Organisation. International Medical Products Anti-counterfeiting Taskforce. 2007. "Principles and Elements for National Legislation against Counterfeit Medical Products." Text endorsed by IMPACT General Meeting, Lisbon, Portugal.

[5] European Parliament. 2006. "Resolution on Counterfeiting Medicinal Products.” Resolution (P6_TA-PROV(2006)0351) September 2006.

[6] Verheugen, G. 2007. "Statement Putting an End to Drug Counterfeiting." Presented at the 1st European Parliamentary Symposium, Brussels, Belgium.

[7] European Parliament. 2008. "Impact Assessment. Commission Staff Working Document: Accompanying Document to the Proposal for a Directive of the
European Parliament and of the Council Amending Directive 2001/83/EC as Regards the Prevention of the Entry into the Lawful Supply Chain of Medicinal Products Which Are Falsified in Relation to Their Identity, History or Source.” EC report SEC (2008) 2674, Brussels.

[8] EUR-Lex. 2011. "Directive 2011/62/EU of the European Parliament and of the Council of 8 June 2011 Amending Directive 2001/83/EC on the Community Code Relating to Medicinal Products for Human Use, as Regards the Prevention of the Entry into the Lawful Supply Chain of Falsified Medicinal Products.” Accessed January 10, 2015. http://eur-lex.europa.eu/legal-content/EN/TXT/?uri=CEL EX\%3A32011L0062

[9] Hristov, E, and Kulaksazova, R. 2008. "Counterfeit Medicinal Products-Introduction in Theory and Practice.” Presented at the 4th Pharmaceutical Symposium on Southeast Europe of the European Generic Association, Istanbul, Turkey.

[10] European Parliament. 2008. "Summary of the Impact Assessment. Commission Staff Working Document: Accompanying Document to the Proposal for a Directive of the European Parliament and of the Council amending Directive 2001/83/EC as Regards the Prevention of the Entry into the Lawful Supply Chain of Medicinal Products Which Are Falsified in Relation to Their Identity, History or Source.” EC Report SEC (2008) 2674, Brussels.

[11] World Health Organisation. 2010. "Preliminary Draft Survey on National Legislation on "Counterfeit medicines"." Report WHO/ACM/1.

[12] National Assembly Bulgaria. 1995. "Bulgarian Pharmaceuticals and Pharmacies in Human Medicine Act." (promulgated in SG, issue 36 of 18 April 1995). Sofia, Bulgaria. (in Bulgarian)

[13] National Assembly Bulgaria. 2007. "Bulgarian Medicinal Products in Human Medicine Act." (Promulgated in SG, Issue 31 of 13 April 2007). Sofia, Bulgaria. (in Bulgarian)

[14] Hristov, E., and Spassova, S. 2010. "Bulgaria Tackles Increasing Numbers of Counterfeit Drugs." German Association of Pharmaceutical Parallel Distributors, Pharmaceutical Dialogue 12, 4-4. 